\title{
Comparative Effects of Physical Training and Metformin in Diabetic Rats
}

\author{
Rafael Fernando Silveira, José Alexandre Curiacos de Almeida Leme*, Cirval Correa de Almeida \\ Junior, Ricardo José Gomes, Clarice Yoshiko Sibuya, Maria Alice Rostom de Mello and \\ Eliete Luciano
}

Department of Physical Education, São Paulo State University (UNESP), Rio Claro, SP, Brazil

\begin{abstract}
Diabetes mellitus is a metabolic disease associated with multiple organ damage, dysfunction and failure. Metformin is widely used to treat diabetes, but regular exercise also improves metabolic control in diabetic individuals and has an important role in the management of this disease. In this work, we compared the effects of metformin and physical training in diabetic male Wistar rats. Four groups of rats were used: ( $n=6$ per group): sedentary control (SC), sedentary diabetic (SD), trained diabetic (DT) and metformin diabetic (MD). Diabetes was induced with alloxan (30 mg/kg, b.w.). The physical training protocol consisted of a $1 \mathrm{~h}$ swimming session/day, five days/week for eight weeks with a load corresponding to $5 \%$ of the body weight. Metformin treatment consisted in $1.4 \mathrm{mg} / \mathrm{ml}$ per day, administered in the drinking water. At the end of the experimental period, the rats were sacrificed and blood was collected to measure serum glucose, insulin and albumin. Glycogen was quantified in gastrocnemius muscle, liver and heart, the protein/DNA ratio was mensured in liver and heart triglycerides was also measured in the heart. Diabetes reduced the serum insulin and liver glycogen levels and the protein/DNA ratio, but increased the serum glucose and heart glycogen levels; there were no significant variations in serum albumin levels. Physical training increased the muscle glycogen level. Physical training and metformin were equally effective in reducing the serum glucose concentration and in restoring the hepatic and cardiac glycogen stores and the hepatic protein/DNA ratio in diabetic rats. These results show that chronic exercise was as effective as metformin in improving the metabolic profile of diabetic rats and in preventing diabetes-induced alterations.
\end{abstract}

Key Words: Diabetes, metabolism, metformin, training.

\section{INTRODUCTION}

Diabetes is currently a major health problem worldwide. Type 1 and type 2 diabetes are characterized by hyperglycemia caused by defects in insulin secretion and/or insulin action that may lead to complications such as nephropathy, retinopathy and cardiovascular disease [1]. In addiction to its primary effects on glucose metabolism, insulin promotes a number of other cellular events such as regulation of ion and amino acid transport, lipid metabolism, glycogen synthesis, gene transcription and mRNA turnover, protein synthesis and degradation and RNA synthesis, in several organs including liver heart and skeletal muscle [2]. Therefore the hypoinsulinism in type 1 diabetes causes several disturbances in liver glucose and fat metabolism [3]. Heart also is an insulin responsive organ and patients with diabetes show an increased risk of heart failure, associated to alterations in fatty acid and decreased glucose consumption [4].

The treatment of diabetes includes nutritional control, physical exercise and appropriate medication [1]. Metformin (dimethylbiguanide) is an antihyperglycemic agent used to treat diabetes. Metformin decreases liver glucose production and intestinal glucose absorption and has variable lipidlowering effects that slow the development of diabetes.

*Address correspondence to this author at the Av. Armando Salles de Oliveira, 1574, ap.72, Piracicaba, São Paulo, Brasil, Cep 13400-000;

E-mail: zecuriacos@terra.com.br
Potential targets for the action of metformin include the insulin receptor (IR), the glucagon receptor, glucose transporters and AMP-activated protein kinase (AMPK) $[5,6]$.

Regular exercise improves metabolic control in diabetic individuals and has an important role in the management of this condition. Several mechanisms may act locally to improve glucose uptake and disposal after exercise. These include increased muscle blood flow, insulin binding to the insulin receptor, insulin receptor turnover and glucose transport by stimulating GLUT4 translocation to the muscle cell surface, thereby attenuating many effects of diabetes $[7,8]$.

Since treatment with metformin and regular exercise are important measures in the treatment and control of diabetes [1], in this study we investigated the effects of physical training and metformin on metabolic parameters in alloxan diabetic rats.

\section{METHODS}

\section{Study Design}

Male Wistar rats (175-200 g, 38 days old) obtained from the Central Animal Breeding Center at UNESP, Botucatu, were used in this study. The rats were housed in the Biodynamic Laboratory in the Department of Physical Education at UNESP-Rio Claro on a $12 \mathrm{~h} \mathrm{light/dark} \mathrm{cycle} \mathrm{with} \mathrm{free}$ access to water and standard rodent chow $\left(\right.$ Purina $\left.^{\circledR}\right)$. The animal experiments were done in accordance with the cur- 
rent Brazilian legislation and the guidelines of the Brazilian College of Animal Experimentation (COBEA).

\section{Induction of Diabetes}

Diabetes was induced by a single intravenous injection of alloxan (30 mg/kg, b.w.; Sigma). Five days later, the plasma glucose concentration was determined in blood samples obtained from rats in the fed state. Rats that were not diabetic $(<14.7 \mathrm{mmol} / \mathrm{L})$ or that were extremely diabetic $(>35.5$ $\mathrm{mmol} / \mathrm{L}$ ) were excluded from the study.

\section{Experimental Design}

Rats were randomly allocated to one of four groups $(n=6$ per group): sedentary control (SC), sedentary diabetic (SD), trained diabetic (DT) and metformin diabetic (MD). The training included daily swimming with a load corresponding to $5 \%$ of the body weight for $1 \mathrm{~h} /$ day, five days/week for eight weeks. Metformin was dissolved in free access water $(1.4 \mathrm{mg} / \mathrm{ml})$ for eight weeks. Along this period, the rats were weighed once a week.

\section{Serum and Tissue Sample Collection}

At the end of the training period, the hematocrit was determined at rest to ensure that the hormone and metabolite concentrations were not influenced by changes in plasma volume. The rats were sacrificed $48 \mathrm{~h}$ after their last training session and blood samples were collected for the determination of glucose and insulin levels. Samples of heart, liver and muscle were collected for the quantification of glycogen and triglycerides (heart), and determination of the protein/DNA ratio (liver and heart).

\section{Analytical Methods}

Serum glucose was measured by a colorimetric method [9] and serum insulin was determined by radioimmunoassay (RIA Coat-A-Count kit/DPC ${ }^{\circledR}$, Los Angeles, CA, USA). Glycogen [10], triglyceride [11], protein [12] and DNA [13] levels were quantified using standard colorimetric assays.

\section{Statistical Analyses}

The results were expressed as the mean \pm SD. All statistical comparisons were done using one-way analysis of variance (ANOVA) followed by the Bonferoni multiple comparisons test. A value of $\mathrm{p}<0.05$ indicated significance.

\section{RESULTS}

Diabetes increased the blood glucose levels, but this increase was attenuated by physical training or the administration of metformin (Table 1). Blood insulin was reduced in all of the diabetic groups. There were no significant differences among the serum albumin levels of the experimental groups but the glycogen content of gastrocnemius muscle was increased in trained diabetic rats.

Fig. (1) shows that diabetes decreased body weight after the sixth week of experiment and both physical training and metformin were able to recover this parameter.

In liver, diabetes reduced the glycogen content and protein/DNA ratio, but these were restored by physical training or treatment with metformin (Fig. 2).
Diabetes also increased the cardiac glycogen level (Fig. 3) but this increase was prevented by both physical training and treatment with metformin. There were no significant alterations in the heart triglyceride content (Fig. 3) or the protein/DNA ratio (Table $\mathbf{3}$ ).

Table 1. Blood Glucose $(\mathrm{mmol} / \mathrm{L})$, Insulin $(\mathrm{ng} / \mathrm{ml})$, Albumin (g/dl) and Gastrocnemius Muscle Glycogen (mg\%) Levels after Eight Weeks of Training or Treatment with Metformin

\begin{tabular}{|c|c|c|c|c|}
\hline Parameters & SC & SD & TD & MD \\
\hline \hline Glucose (mmol/L) & $5.9 \pm 0.7$ & $21.3 \pm 3.3^{\mathrm{a}}$ & $13 \pm 6.7$ & $14 \pm 6.7$ \\
\hline Insulin $(\mathrm{ng} / \mathrm{ml})$ & $0.47 \pm 0.2$ & $0.12 \pm 0.1^{\mathrm{a}}$ & $0.14 \pm 0.1^{\mathrm{a}}$ & $0.2 \pm 0.1^{\mathrm{a}}$ \\
\hline Albumin $(\mathrm{g} / \mathrm{dl})$ & $3.4 \pm 0.3$ & $3.5 \pm 0.3$ & $3.6 \pm 0.4$ & $3.5 \pm 0.3$ \\
\hline Muscle glycogen $(\mathrm{mg} \%)$ & $2.9 \pm 0.4$ & $2.7 \pm 0.5$ & $4.3 \pm 1.4^{\mathrm{b}}$ & $2.7 \pm 1.4$ \\
\hline
\end{tabular}

The values are the mean \pm SD of 6 rats/group. SC - sedentary control, SD - sedentary diabetic, TD - trained diabetic, MD - metformin diabetic. ${ }^{\mathrm{a}} \mathrm{p}<0.05$ compared to SC, ${ }^{b} \mathrm{p}<0.05$ compared to SD (ANOVA)

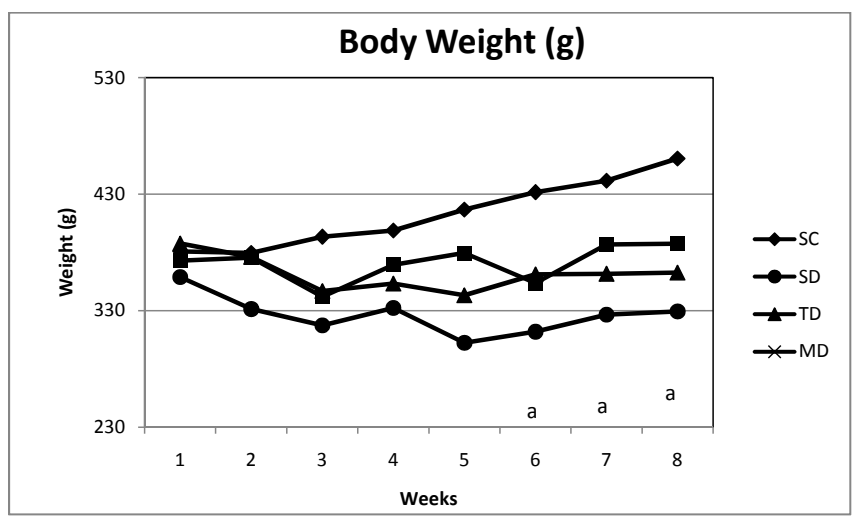

Fig. (1). Body weight (g) during 8 weeks of experiment. Values are means \pm SD; $n=6$ per group. SC (Sedentary Control); SD (Sedentary Diabetic); TD (Trained Diabetic); MD (Metformin Diabetic). ${ }^{\mathrm{a}} \mathrm{p}<0.05$ compared to SC (ANOVA).

\section{DISCUSSION}

Physical training and the administration of metformin are important approaches in the treatment of diabetes. Metformin is widely used for the treatment of diabetes mellitus. It ameliorates hyperglycemia without stimulating insulin secretion, promoting weight gain or causing hypoglycemia $[14,15]$. In addiction, metformin has beneficial effects on circulation lipids linked to increased cardiovascular risk [1416]. On the other hand, endurance training increases insulinstimulated muscle glucose transport and leads to improved metabolic control in diabetic patients, preventing diabetes complications [8]. In this study, we compared the effects of physical training or treatment with metformin on several metabolic parameters in diabetic rats

As expected, alloxan-induced diabetes reduced the blood insulin levels in all of the diabetic groups (SD, TD and MD) and increased the blood sugar levels in sedentary diabetes. Physical training and metformin restored blood glucose lev- 
els in TD and MD rats. Chronic exercise reduces serum glucose in diabetic animals and humans $[17,18]$, improves glucose uptake, increases muscle blood flow and insulin binding to the insulin receptor, and enhances insulin receptor turnover. The enhanced responsiveness to insulin results partly from modulation of the insulin signaling pathway at different levels [19]. In particular, the insulin receptor substrate (IRS)/phosphoinositol 3 (PI3)-kinase pathway may be linked to the activation of glucose transport and glycogen synthesis in muscle, and an increase in this association in the muscle of trained animals and humans may have an important role in the responsiveness to insulin $[9,20]$. Metformin also decreases glycemia reducing gluconeogenesis, lowers circulating lipid (VLDL, triglycerides and free fatty acids) levels, increases GLUT-4 gene expression, and attenuates hepatic PEPCK gene expression. The effects of metformin involve the insulin receptor, the glucagon receptor, glucose transporters and AMPK [21]. The lack of significant variations in the serum albumin concentrations among the groups indicated that dehydration was not an important factor in the changes seen here [22].
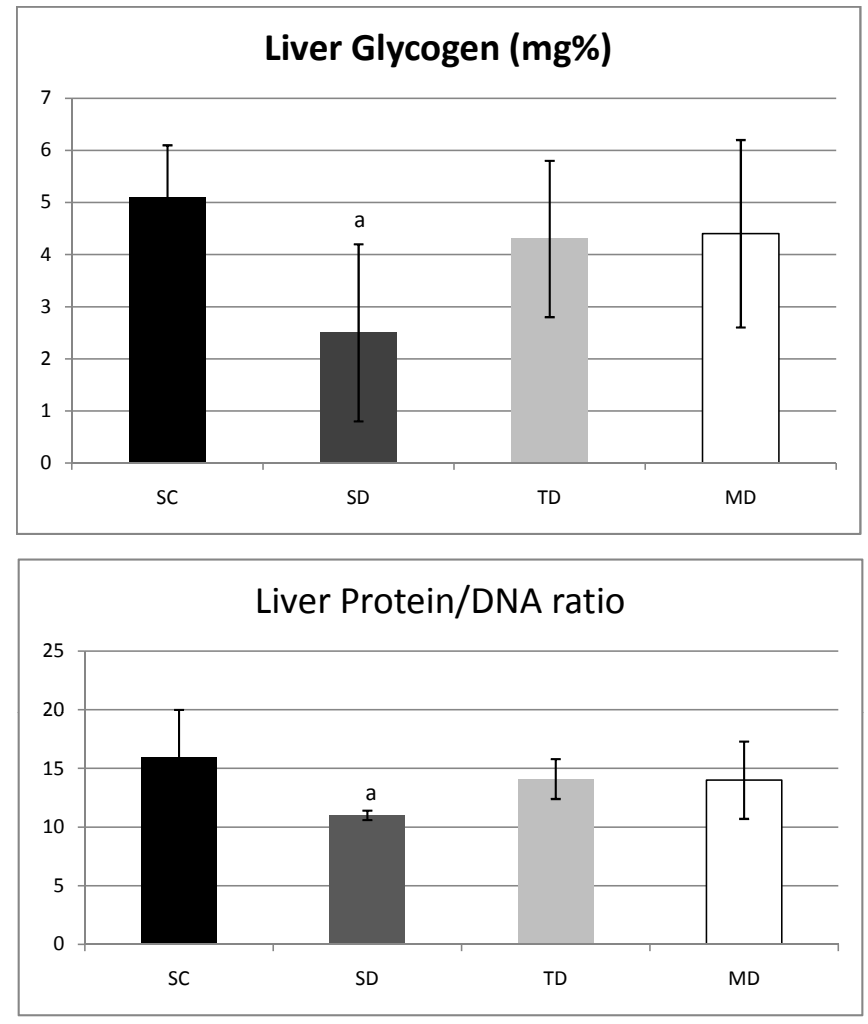

Fig. (2). Liver glycogen (mg\%) levels and Protein/DNA ratio levels after 8 weeks of experiment. Values are means $\pm S D ; n=6$ per group. SC (Sedentary Control); SD (Sedentary Diabetic); TD (Trained Diabetic); MD (Metformin Diabetic). ${ }^{a} \mathrm{p}<0.05$ compared to SC (ANOVA).

Physical training increased the muscle glycogen content in diabetic rats. The effects of exercise on muscle glycogen are well known $[23,24]$. The exercise-induced replenishment of muscle glycogen seen here in diabetic rats agreed with the reported correlation between PI3-kinase activity and glycogen synthesis in muscle [23]. Metformin increases AMPK activity, thereby increasing glucose consumption in skeletal muscle of diabetics, with a consequent decrease in muscle glycogen concentrations [25]. However, the lack of change in muscle glycogen seen here in diabetic rats meant that there were also no changes in metformin-treated diabetic rats.
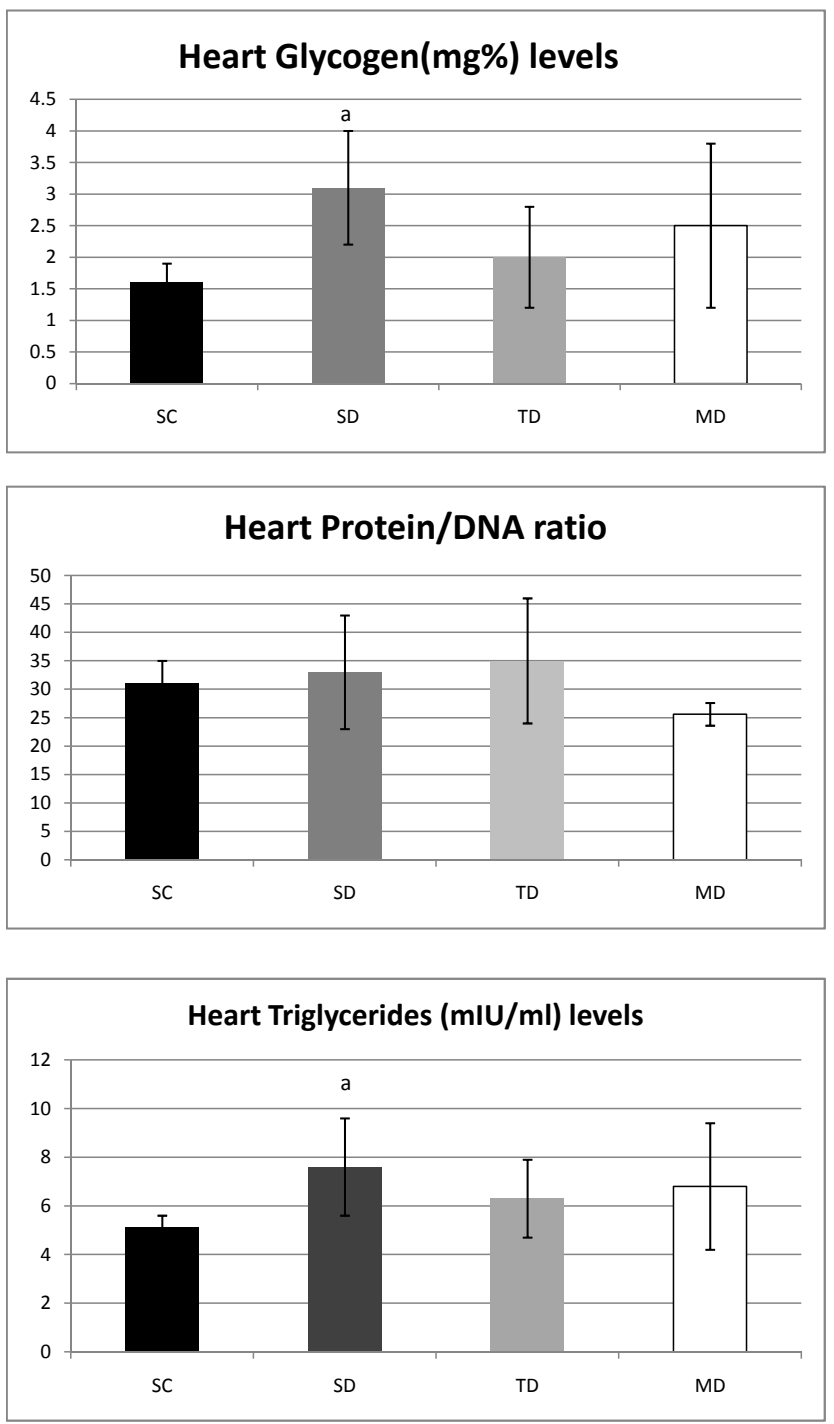

Fig. (3). Cardiac glycogen (mg\%) levels, Protein/DNA ratio and triglycerides $(\mathrm{mIU} / \mathrm{ml})$ levels after 8 weeks of experiment. Values are means $\pm \mathrm{SD} ; \mathrm{n}=6$ per group. SC (Sedentary Control); SD (Sedentary Diabetic); TD (Trained Diabetic); MD (Metformin Diabetic). ap $<0.05$ compared to SC (ANOVA).

Diabetes increased the heart glycogen content, whereas physical training and metformin attenuated this increase. An increase in glycogen synthase activity enhances the heart glycogen content [26] and, in diabetic rats, there is also a decrease in GLUT 4 translocation and protein kinase B activity [27]. The findings of the present study in diabetic rats agree with previous investigations that reported a similar decrease in cardiac glycogen content after physical training in animals [28]. The decrease in liver glycogen in diabetic rats was prevented by physical training or metformin. Chronic exercise and metformin active hepatic AMPK to 
adversely affect hepatocyte glucose production by inhibiting gluconeogenesis and glucogenolysis [29]. The changes seen here may have resulted from a higher total hepatic glycogen synthetase activity and a lower phosphorylase activity that increased the hepatic glycogen content [30].

The storage of triglycerides and the mobilization of this energy source as free fatty acids are regulated by genetic, nutritional, hormonal and paracrine factors [31]. As shown here, there were no significant changes in the heart triglyceride levels in any of the groups. Triglyceride accumulation is common in diabetic hearts and may reflect both the inhibition of lipolysis and enhanced lipogenesis resulting from high levels of exogenous free fatty acids and glucose. The lack of significant changes seen here may be related to a decrease in myocyte neutral lipase activity and an increase in lipoprotein lipase activity [26, 32-35].

Tissue growth can be assessed by estimating the cellular protein/DNA ratio [35]. In the present study, neither diabetes nor any of the interventions (physical training or metformin) significantly altered the cardiac myocyte size in rats (there were no differences in the protein/DNA ratios). In contrast, cellular hypotrophy was observed in the liver of diabetic rats but was prevented by physical training or treatment with metformin. This could be explained, at last in part, by the insulinopenic conditions of the diabetic rats that decrease protein synthesis in rat liver and decreases protein degradation, that was recovered by physical training and metformin administration $[5,33,36]$.

In conclusion, the results of the present study show that chronic exercise is as effective as metformin in improving the metabolic profile of diabetic rats and in preventing diabetes-induced alterations. Future studies should assess the effects of combined metformin treatment and exercise training on metabolic parameters in diabetic rats.

\section{ACKNOWLEDGEMENTS}

The authors wish to thank Eduardo Custódio and José Roberto R. Silva for technical assistance. This work was supported by CNPQ.

\section{REFERENCES}

[1] American Diabetes Association. Diagnosis and classification of Diabetes Mellitus. Diabet. Care, 2006, 29, S43.

[2] Cheatham, B.; Kahn, C.R. Endocr. Rev., 1995, 16(2), 117.

[3] An, D.; Rodrigues, B. Am. J. Physiol. Heart Circ. Physiol., 2006, 291(4), H1489.

[4] Large, V.; Beylot, M. Diabetes, 1999, 48(6), 1251.

[5] Cheng, J.T.; Huang, C.C.; Liu, I.M.; Tzeng, T.F.; Chang, C.J. Diabetes, 2006, 55(3), 819 .
[6] Leme, J.A.C.A.; Gomes, R.J.; Mello, M.A.R.; Luciano, E. Growth Factors, 2007, 25(1), 9.

[7] Montanari, D.; Yin, H.; Dobrzynski, E. Agata J, Yoshida H, Chao J, Chao L. Diabetes, 2005, 54, 1573.

[8] Zinman, B.; Ruderman, N.; Campaigne, B.N.; Devlin, J.T.; Schneider, S.H.; Diabet. Care, 2004, 27, S58.

[9] Henry, R.J.; Cannon, D.C.; Winkelman, J. Clin. Chem. Prin. Tech. 2nd ed. New York: Harper and Row Publishers Inc. Kraus, 2002.

[10] Dubois, B.; Gilles, K.A.; Hamilton, J.K.; Smith, F. Anal. Chem., 1956, 28, 350 .

[11] Belmonte, M.; Aoki, M.; Tavares, F.; Seelaender, M.C. Med. Sci. Sports Exerc., 2004, 36(1), 60.

[12] Lowry, O.H.; Rosebrough, N.J.; Farr, A.L.; Randall, R.J. J. Bio. Chem., 1951, 193, 265.

[13] Giles, K.W.; Myers, A. Nature, 1965, 206, 93.

[14] Stumvoll, M.; Nurjhan, N.; Perriello, G.; Dailey, G.; Gerich, J.E. N. Engl. J. Med., 1995, 333(9), 550.

[15] Wiernsperger, N.F.; Bailey, C.J. Drugs, 1999, 58, 75.

[16] Wu, M.S.; Johnston, P.; Sheu, W.H.; Hollenbeck, C.B.; Jeng, C.Y.; Goldfine, I.D.; Chen, Y.D.; Reaven, G.M. Diabet. Care, 1990, 13(1), 1 .

[17] Giles, K.W.; Myers, A. Nature, 1965, 206, 93

[18] Farrel, P.A.; Fedele, M.J.; Hernandez, J.; Fluckey, J.D.; Miller J.L.; Lang, C.H.; Vary, T.C. J. Appl. Physiol., 1999, 87, 1075.

[19] Gomes, R.J.; Mello, M.A.R.; Caetano, F.H.; Sibuya, C.Y.; Anaruma, C.A.; Rogatto, G.P.; Pauli, J.R.; Luciano, E. Growth Horm. IGF Res., 2006, 16(5-6), 326.

[20] Lim, G.J.; Kang, H.J.; Stewart, K.J. Singapore Med. J., 2004, 45, 62.

[21] Luciano, E.; Carneiro, E.M.; Carvalho, C.R.O.; Carvalheira, J.B.C.; Peres, S.B.; Reis, M.A.B.; Saad, M.J.A.; Boschero, A.C.; Velloso, L.A. Eur. J. Endocrinol., 2002, 147, 149.

[22] Bloomgarden, Z.T. Diabet. Care, 2004, 27(5), 1227.

[23] Abrass, C.K. Am. J. Nephrol., 1984, 4, 337.

[24] Gobbato, C.A.; Sibuya, C.Y.; Kokubun, E.; Mello, M.A.R. Med. Sci. Sports Exerc., 1997, 29(5), S20.

[25] Thrailkil, K.M. Diabet. Technol. Ther., 2000, 2, 69.

[26] Paulson, D.J.; Crass, M.F. Am. J. Physiol., 1982, 242(6), H1084.

[27] Paulson, D.J.; Mathews, R.; Bowman, J.; Zhao J. J. Appl. Physiol., 1992, 73, 265.

[28] Lajoie,C.; Calderone, A.; Trudeau, F.; Lavoie, N.; Massicotte, G.; Gagnon, S.; Béliveau, L. J. Appl. Physiol., 2004, 96, 1606.

[29] Luciano, E., Lima, F.B. Rev. Cien. Biom., 1997, 18, 47.

[30] Zhou, G.; Myers, R.; Li, Y.; Chen, Y.; Shen, X.; Fenyk-Melody, J.; Wu, M.; Ventre, J.; Doebber, T.; Fuji, N.; Musi, N.; Hirshman, M.F.; Goodyear, L.J.; Moller, D.E. J. Clin. Invest., 2001, 108(8), 1167.

[31] Galbo, H.; Saugmann, P.; Richter, E.A. Acta Physiol. Scand., 1979, 107, 269.

[32] Lewis, G.F.; Carpentier, A.; Adeli, K.; Giacca, A. Endocr. Rev., 2002, 23, 201.

[33] Pulinilkunnil, T.; Rodrigues, B. Cardiovasc. Res., 2006, 69(2), 329.

[34] Reaven, E.P., Peterson, D.T., Reaven, G.M. J. Clin. Invest., 1973, $52,248$.

[35] Ramirez, I.; Severson, D.L. Biochem. J., 1986, 238(1), 233.

[36] Rossetti, L.; DeFronzo, R.A.; Gherzi, R.; Stein, P.; Andraghetti, G.; Falzetti, G.; Shulman, G.I.; Klein-Robbenhaar, E.; Cordera, R. Metabolism, 1990, 39(4), 425. 